\title{
Follicular lymphoma in young adults: a clinicopathological and molecular study of 200 patients
}

Ívison X Duarte ${ }^{1,2}$, Pollyanna Domeny-Duarte ${ }^{1}$, Sheila CL Wludarski ${ }^{1}$, Yasodha Natkunam ${ }^{3}$ and Carlos E Bacchi ${ }^{1,2}$

${ }^{1}$ Laboratório Bacchi/Consultoria em Patologia, Botucatu, Brazil; ${ }^{2}$ Department of Pathology, University of São Paulo, São Paulo, Brazil and ${ }^{3}$ Department of Pathology, Stanford University School of Medicine, Stanford, CA, USA

Follicular lymphoma is clinically heterogenous, and therefore necessitates the identification of prognostic markers to stratify risk groups and optimize clinical management. It is relatively rare in patients younger than 40 years, and the clinicopathologic characteristics and biological behavior in this age group are poorly understood. In the current study, samples from a cohort of 200 patients between 19 and 40 years were evaluated retrospectively with respect to clinical, histologic, and genetic features. These were then correlated with clinical outcome. The median age at presentation was 35 years with a slight female prepoderance $(56 \%)$. Most of the cases are presented with nodal disease $(90 \%)$. Concomitant follicular lymphoma and diffuse large B-cell lymphoma were observed in 7 (4\%) patients. Immunohistologic studies showed the expression of CD10 (91\%), BCL6 (97\%), BCL2 (95\%), MUM1/IRF4 (12\%), MDM2 (17\%), and CD23 (25\%). BCL2 rearrangement was present in $74 \%$, and BCL6 in $20 \%$. The estimated overall survival of patients was 13 years (mean). The presence of anemia, elevated lactose dehydrogenase, bone marrow involvement, and high-risk follicular lymphoma international prognostic index correlated with adverse overall survival. Our findings revealed that follicular lymphoma in young adults demonstrate similarities with that of older adults, including the frequency of presentation at various anatomic sites, grade, and adverse prognostic factors.

Modern Pathology (2013) 26, 1183-1196; doi:10.1038/modpathol.2013.50; published online 19 April 2013

Keywords: follicular lymphoma; immunohistochemistry; indolent lymphoma; non-Hodgkin lymphoma; survival; young adults

Follicular lymphoma is characterized by a nodular growth pattern and the $t(14 ; 18)$ translocation, which results in the overexpression of the anti-apoptotic protein, BCL2.1,2 It is the commonest form of indolent B-cell lymphoma, and is clinically manifested with multiple relapses and remissions. The median age at diagnosis is about 60 years and there is a slight female predominance. ${ }^{3}$ Despite recent improvements in survival, follicular lymphoma remains an incurable disease, with a median overall survival of $\sim 14$ years. ${ }^{4}$ This clinical outcome is significantly worse than that in a matched cohort of the general population, especially in younger age groups. Although a subset of patients

Correspondence: Dr CE Bacchi, MD, PhD, Laboratório Bacchi/ Consultoria em Patologia, Rua Major Leônidas Cardoso 739, Botucatu 18602-010, Brazil.

E-mail: bacchi@conspat.com.br

Received 10 December 2012; revised 27 January 2013; accepted 27 January 2013; published online 19 April 2013 remain alive for decades without treatment, ${ }^{5} \sim 15 \%$ of them succumb to the disease within 2 years of initial diagnosis, whereas others develop progressive disease or transform to a higher-grade lymphoma. ${ }^{6}$ Even among patients who demonstrate an indolent disease course, many show an advanced stage at diagnosis (III or IV) with the involvement of multiple lymph node sites, as well as the bone marrow at presentation. ${ }^{7}$

Follicular lymphoma is rare under the age of 18 years and accounts for $1-2.5 \%$ of lymphomas occurring in that age group. It is typically localized, demonstrates specific clinical, morphologic, immunohistochemical, and genetic features, and confers a more favorable clinical outcome than its adult counterpart. ${ }^{8,9}$ In contrast, the biologic behavior of follicular lymphoma in young adults, defined as 18-40 years of age, has not been well-studied. Follicular lymphoma in this age group represents $15-20 \%$ of all lymphoma diagnoses. ${ }^{10} \mathrm{~A}$ populationbased study of 46 young adults reported improved 
overall survival compared with adult follicular lymphoma; however, that study was conducted in the pre-rituximab era. ${ }^{11}$

Recent advances in therapeutic modalities such as the proteasome inhibitor bortezomib, bendamustine, and the fully humanized anti-CD20 antibody, ${ }^{4,12}$ in addition to hematopoietic stem cell transplantation, have shown improved efficacy in the treatment of lymphomas. Additionally, most studies show that about $20 \%$ of patients never relapse or die from the disease, for example, one study in the pre-rituximab era showed no recurrence of disease in a cohort of patients who were followed for 20 years. ${ }^{5}$ These studies have illustrated that the biological behavior of follicular lymphoma is markedly heterogeneous. Consequently, more precise information on prognostication as well as identification of predictive markers of response is necessary to achieve the goal of individualized risk-adapted therapy. We therefore sought to investigate a series of 200 patients between the ages of 19 and 40 years, who were diagnosed with follicular lymphoma, to better understand its clinicopathological, immunophenotypic, and molecular features.

\section{Materials and methods}

\section{Case Selection}

All cases were obtained from the files of a single institution, Consultoria em Patologia, a large reference anatomic pathology laboratory located in São Paulo State, Brazil. This study was based on a review of 2600 cases previously diagnosed as follicular lymphoma between the years 1997 and 2011. Inclusion criteria were as follows: (1) fulfilled histologic and imunophenotypic criteria for the diagnosis of follicular lymphoma; (2) age between 19 and 40 years; and (3) non cutaneous involvement. Two hundred patients fulfilled these criteria. Adequate follow-up and/or survival information was available in 121 patients. Clinical information was recorded for each patient and included age, gender, date of initial diagnosis, symptoms and signs at presentation, clinical and/or pathological stage, and pertinent data related to treatment. As virtually all cases were received in consultation from outside institutions, clinical data were obtained from the primary physicians at the referring institutions. Patients were staged according to the Ann Arbor system, and the Follicular Lymphoma International Prognostic Index (FLIPI) was calculated. Systemic symptoms were regarded as present when the patient had unexplained fever, night sweats, or weight loss of $>10 \%$ of initial body weight. Treatment information included type of therapy (radiation therapy, chemotherapy, combined therapy, or no therapy), response to therapy (complete remission, partial remission, or no remission); the duration of the initial response, the patient's survival status (dead or alive, with or without evidence of lymphoma), and the survival time was assessed in months. This study had the approval of the Ethics Committee of the University of São Paulo (protocol 110/10, 05.19.2010).

\section{Tissue Microarray Construction}

Paraffin blocks of 159 cases were available and used for tissue microarray construction with the aid of a tissue arrayer (Beecher Instruments, Sun Prairie, WI, USA). One tumor core of $2.0 \mathrm{~mm}$ taken from the original paraffin blocks represented each case. Serial sections of $3 \mu \mathrm{m}$ were cut from the tissue array blocks, and used for immunohistochemical and fluorescence in situ hybridization (FISH) analyses. In the remaining cases, the original slides with whole histological sections were avaliable and used for analysis.

\section{Histologic Evaluation}

The histologic sections of all cases were stained by hematoxylin and eosin, and were reviewed, with all the diagnoses confirmed and graded by two of the authors (CEB and IXD) according to the criteria described by the 2008-WHO classification of hematopoietic diseases. ${ }^{7}$ Particular morphologic features were evaluated, such as: (a) presence or absence of mantle zones; (b) semi-quantification of the number of tumor-associated macrophages imparting a starry-sky appearance (0, no macrophage; $1+, 1-5$ macrophages per high-power field (HPF); 2+, 6-15 macrophages/HPF; 3+, >15 macrophages/HPF); (c) estimation of fibrosis $(0,1+, 2+$, and $3+$ in $3+)$; and (d) presence or absence of diffuse areas.

\section{Immunohistologic Studies}

Immunohistologic studies were performed on cut sections of the tissue microarray paraffin blocks using the Novolink polymer (Novocastra, Newcastle Upon Tyne, UK), as the detection system and an epitope-retrieval method was applied as needed for each specific antibody; diaminobenzidine (DAB) was the chromogen. Information on antibodies used and their dilutions are summarized in Table 1. In the evaluation of the following immunohistochemistry markers, the results were considered as either positive or negative in the tumor cells: CD3, CD10, CD20, CD23, BCL2, BCL6, kappa and lambda immunoglobulin light chains, and MUM1/IRF4. The Ki-67 proliferative index was evaluated using the monoclonal MIB-1 antibody and assigned a percentage value that was calculated by scoring 500 tumor cell nuclei: the cases were divided into groups of $<50$ and $\geq 50 \%$ staining according to Ki-67 immunostaining. For MDM2 expression, the cutoff used was $<20$ and $\geq 20 \%$ of positive 
Table 1 Specifications of primary antibodies, source, epitope retrieval, and criteria for the cutoff

\begin{tabular}{llllll}
\hline Antigen & Clone & Dilution & Source & $\begin{array}{l}\text { Epitope } \\
\text { retrieval }\end{array}$ & Cutoff \\
\hline CD23 & SP23 & $1: 200$ & Neomarkers & M.POL & Any \\
CD20 & L26 & $1: 1200$ & DAKO & MM.ABC & Any \\
CD10 & 56 C6 & $1: 200$ & Novocastra & S.POL & Any \\
CD3 & 565 & $1: 800$ & Novocastra & MM.ABC & Any \\
BCL2 & 124 & $1: 2000$ & DAKO & MM.ABC & Any \\
BCL6 & 564 & $1: 2400$ & Novocastra & S.POL & Any \\
Ki-67 & MIB-1 & $1: 4800$ & DAKO & S.POL & $\geq 50 \%$ \\
kappa & A8B5 & $1: 200$ & DAKO & MM.ABC & Any \\
lambda & N10/2 & $1: 400$ & Neomarkers & S.POL & Any \\
MDM2 & IF2 & $1: 2400$ & Zymed & S.POL & $\geq 20 \%$ \\
MUM1/ & MUM1P & $1: 1200$ & DAKO & S.POL & Any \\
IRF4 & & & & & \\
\end{tabular}

Abbreviations: FL, MM.ABC: microwave, mouse avidin biotin complex; M.POL: microwave, polymer; S.POL: steamer, polymer.

DAKO (Carpinteria, CA, USA); Neomarkers/Lab Vision (Fremont, CA,

USA); Novocastra (Newcastle, UK); Zymed (San Francisco, CA, USA).

neoplastic cells. Additionally, CD23 was also used to visualize the follicular dendritic cells meshwork, and its immunostaing pattern was classified as 'preserved', 'disrupted',or 'absent'.

\section{FISH}

FISH analysis was performed using a $3-\mu \mathrm{m}$-thick TMA section, according to the standard procedures. LSI BCL2 Dual Color Break Apart Rearrangement Probe (Vysis, Downers Grove, IL, USA) was used to detect BCL2 rearrangement. LSI BCL6 Dual Color, Break Apart Rearrangement Probe (Vysis) was used to detect different translocations involving the BCL6 gene. DAPI (Vysis) was used for nuclear counterstaining. The slides were evaluated using spectrum orange- and spectrum green filters (Chroma Technology GmbH, Fuerstenfeldbruck, Germany) on a Zeiss Axio Imager M1 fluorescence microscope (Carl Zeiss AG, Germany) using the assistance of Metafer 4 Imaging Software (Metasystems, Altlussheim, Germany). A positive case was defined when the mean number of positive tiles detected was 3 s.d.'s above the mean of a negative control (reactive lymphoid tissue). The threshold established was $1.8 \%$ for BCL2 and $2.2 \%$ for BCL6 (the mean of the negative control group was $0.65 \pm 0.38$ and $0.75 \pm 0.48 \%$, respectively).

\section{Statistical Analysis}

All statistical analyses were performed using the software IBM SPSS Statistics version 19. For all the variables evaluated, frequency distributions were defined. Life tables were produced for all variables. The Kaplan-Meier technique was applied based on these life tables to evaluate the influence of variables on the survival time. The Breslow statistic was used for comparative tests of survival curves. Average survival times were estimated whenever possible on the basis of this technique. Confidence intervals for average survival times were obtained with 95\% confidence coefficient. To estimate the statistical odds ratio, we employed the logistic regression technique. The significance level for all tests was fixed at 0.05 , and for all tests, the descriptive level (p) was calculated to observed statistics. Overall survival was calculated from the date of diagnosis to that of death or last follow-up. ${ }^{13,14}$

\section{Hierarchical Clustering}

Unsupervised hierarchical clustering of the cases based on clinicopathologic variables was performed using Cluster $3.0^{15}$ and visualized using Java TreeView. ${ }^{16}$

\section{Results}

\section{Clinical Features}

Age and anatomic location. Of the 2600 patients of all ages who were diagnosed at our institution as having follicular lymphoma in a 14-year period (1997-2011), 200 (8\%) patients were in the age group between 19 and 40 years. Eighty-seven patients were men $(44 \%)$ and 113 women (56\%). The median age was 35 years. Twenty cases $(10 \%)$ presented with extranodal and 180 (90\%) with nodal disease. The most common nodal anatomic site was the cervical lymph nodes $(30 \%)$, followed by the inguinal lymph nodes $(19 \%)$. The tonsil was the most frequent extranodal location. There was no statistical difference with respect to survival in relation to anatomic site of involvement by follicular lymphoma (Figure 1a).

Follow-up and survival. Information on survival was complete in 121 cases. One hundred and three patients were alive, and 18 were dead. One patient died of an unrelated cause. The estimation of overall survival in all patients was $13.4 \pm 0.8$ years. There was no difference in overall survival between patients $\leq 30$ years compared with 31-40 years. However, life expectancy was reduced significantly to $5.8 \pm 1.4$ years in subjects with hemoglobin $<12 \mathrm{~g} / \mathrm{dl} \quad(n=72 ; P<0.05 ;$ Figure 1b). Elevated serum lactate dehydrogenase and bone marrow involvement also negatively had an impact on survival, which was diminished to $7.4 \pm 1.6$ $(n=70 ; \quad P<0.05) \quad$ and $8.3 \pm 1.1 \quad$ years $\quad(n=75$; $P<0.05$ ), respectivelly (Figures $1 \mathrm{c}$ and $\mathrm{d}$ ). In the evaluation of these three variables in terms of life status, it was observed that the odds ratio was 24.0, 11.8 , and $18.4 \quad(P<0.05)$, respectively. Poor risk FLIPI $(\geq 3)$ was associated with reduced survival of $6.3 \pm 1.8$ years $(n=73 ; P<0.05$; Figure1e) with an odds ratio of 11. The Ann Arbor stage did not have a 

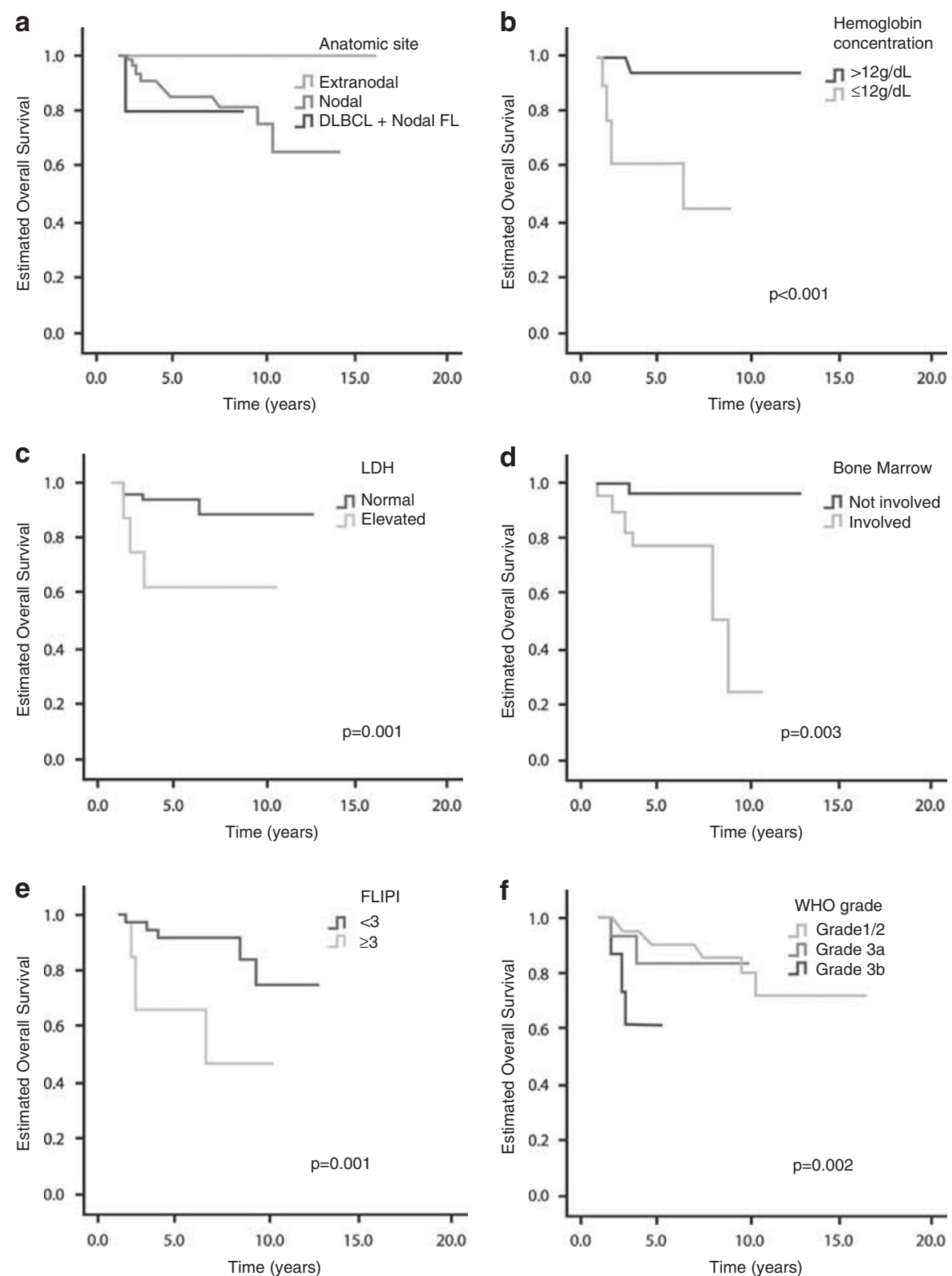

Figure 1 (a) Kaplan-Meier overall survival curve in the set of 126 patients selected according to anatomic site. (b) Kaplan-Meier overall survival curve in the set of 72 patients selected according to hemoglobin concentration. (c) Kaplan-Meier overall survival curve in the set of 70 patients selected according to lactate dehydrogenase. (d) Kaplan-Meier overall survival curve in the set of 75 patients selected according to bone marrow involvement. (e) Kaplan-Meier overall survival curve in the set of 78 patients selected according to FLIPI. (f) Kaplan-Meier overall survival curve in the set of 121 patients selected according to histological grading.

significant impact on life status, although the $P$-value supports a strong trend towards decreased survival for patients with stage IV disease.

Detailed information on treatment was obtained in 79 cases. Most patients were treated on a cyclophosphamide, doxorubicin, vincristine, and prednisone-based chemotherapy regimen (CHOP); 46 patients also received rituximab. Involved-field irradiation was used in 23 patients (Table 2); in 2 of these patients, radiotherapy was the only treatment modality used. Two patients were followed without any treatment. Forty-nine patients achieved complete clinical remission (62\%), and 30 developed recurrence $(38 \%)$.

Histological and immunohistochemistry findings. Histologically, all 200 cases had a predominant nodular growth pattern (Figure 2a). In 37 cases $(19 \%)$, there were closely packed neoplastic follicles, and in 45 cases (23\%), an extensive interfollicular neoplastic infiltrate was present. Most of the cases had the typical attenuated or lack of mantle zones, but 32 cases $(16 \%)$ had at least focally well-formed mantle zones. Diffuse areas, 
Table 2 Clinical information and anatomical site distribution on 200 cases of follicular lymphoma in young patients

\begin{tabular}{|c|c|c|c|c|}
\hline & Extranodal FL & Nodal FL & Nodal FL $+D L B C L$ & Total \\
\hline Total (\%(cases)) & $10(20)$ & $83(173)$ & $4(7)$ & 200 \\
\hline \multicolumn{5}{|l|}{ Age (years) } \\
\hline Median & 35 & 35 & 35 & 35 \\
\hline Range & $23-40$ & $19-40$ & $22-39$ & $19-40$ \\
\hline$M: F$ & 9:11 & $75: 98$ & $3: 4$ & $87: 113$ \\
\hline \multirow[t]{10}{*}{ Anatomic sites } & Tonsil (5) & Abdominal (9) & Cervical (3) & - \\
\hline & Duodenum (2) & Axillary (18) & Axillary (1) & - \\
\hline & Stomach (1) & Cervical (63) & Retroperitoneal (1) & - \\
\hline & Salivary gland (3) & Supraclavicular (7) & Mesenteric (1) & - \\
\hline & Justa-ureteral (1) & Inguinal (40) & Not specified (1) & - \\
\hline & Breast (1) & Mediastinal (1) & & - \\
\hline & Bone (2) & Mesenteric (6) & & - \\
\hline & Peritoneum (1) & Retroperitoneal (7) & & - \\
\hline & Lung (2) & Not specified (22) & & - \\
\hline & Thyroid (2) & & & - \\
\hline \multicolumn{5}{|l|}{ Clinical data $(\%(+))$} \\
\hline None & $40(8)$ & $40(70)$ & 14(1) & $40(79)$ \\
\hline Complete & $45(9)$ & $38(66)$ & $62(5)$ & $40(80)$ \\
\hline Only survival data & $15(3)$ & $22(37)$ & $14(1)$ & $20(41)$ \\
\hline \multicolumn{5}{|l|}{ Stage $(\%(+/$ tested $))$} \\
\hline I & $55(5 / 9)$ & $14(10 / 71)$ & $20(1 / 5)$ & $19(16 / 85)$ \\
\hline II & 0 & $17(12 / 71)$ & $20(1 / 5)$ & 15(13/85) \\
\hline III & 0 & $28(20 / 71)$ & $20(1 / 5)$ & $25(21 / 85)$ \\
\hline IV & $45(4 / 9)$ & $41(29 / 71)$ & $40(2 / 5)$ & $41(35 / 85)$ \\
\hline B symptoms & $22(2 / 9)$ & $39(27 / 70)$ & $60(3 / 5)$ & $38(32 / 84)$ \\
\hline Elevated LDH level & $12(1 / 8)$ & $12(7 / 58)$ & $0 / 4$ & $11(8 / 70)$ \\
\hline Anemia (HB <12 g/dl) & $0(0 / 8)$ & $17(10 / 60)$ & $0 / 4$ & $14(10 / 72)$ \\
\hline Bone marrow involvement & $11(1 / 9)$ & $39(24 / 62)$ & $0 / 4$ & $33(25 / 75)$ \\
\hline \multicolumn{5}{|l|}{ FLIPI score } \\
\hline Low risk $(0-1)$ & $100(8 / 8)$ & $53(31 / 58)$ & $50(2 / 4)$ & $59(41 / 70)$ \\
\hline Intermediate (2) & 0 & $33(19 / 58)$ & $50(2 / 4)$ & $30(21 / 70)$ \\
\hline Poor risk (3-4) & 0 & $14(8 / 58)$ & 0 & $11(8 / 70)$ \\
\hline Chemotherapy & 7 & 63 & 5 & 75 \\
\hline $\mathrm{CHOP}+$ rituximab & 5 & 36 & 3 & 44 \\
\hline CVP + rituximab & - & 2 & - & 2 \\
\hline CHOP & 2 & 18 & 2 & 22 \\
\hline CVP & - & 1 & - & 1 \\
\hline Fludarabin & - & 3 & - & 3 \\
\hline MINE & - & 1 & - & 1 \\
\hline ProMACE-CytaBOM & - & 2 & - & 2 \\
\hline Watch and wait & - & 2 & - & 2 \\
\hline Radiation therapy & 4 & 18 & 1 & 23 \\
\hline Plus chemotherapy & 3 & 17 & 1 & 21 \\
\hline Radiation alone & 1 & 1 & - & 2 \\
\hline
\end{tabular}

Abbreviations: CHOP (Cyclophosphamide, Doxorubicin, Vincristine and Prednisolone); CVP (Cyclophosphamide, Vincristine and Prednisolone); CytaBOM (cytarabine/bleomycin/vincristine/methotrexate) DLBCL: diffuse large B-cell lymphoma; FL: follicular lymphoma; FLIPI: follicular lymphoma international prognostic index; Hb: hemoglobulin; LDH: lactate dehydrogenase; MINE (mesna, ifosfamide, mitoxantrone, and etoposide); ProMACE (prednisone/methotrexate/doxorubicin/cyclophosphamide/etoposide).

defined as sheets of neoplastic cells in the absence of a nodular pattern, as assessed by CD23 immunostaining, were present in $25(12 \%)$ of the nodal follicular lymphoma. One case corresponded to the 'floral' variant of follicular lymphoma. Prominent fibrosis, follicular and/or interfollicular, was a feature seen in 17 cases (9\%; Figure 2b). In all cases, neoplastic follicles were composed of a variable proportion of centrocytes and centroblasts.
Grading according to WHO criteria was distributed as follows: grade $1(n=90 ; 45 \%)$; grade $2(n=63$; $32 \%)$; grade $3 \mathrm{~A}(n=33 ; 16 \%)$; and grade $3 \mathrm{~B}(n=14$; $7 \%)$. Only grade 3B was related to worse overall survival (Figure 1f). Although all specimens were obtained at initial diagnosis before the institution of any treatment, a simultaneous diffuse large B-cell lymphoma component was noted in 7 cases $(4 \%)$. In 5 cases, there were eosinophilic cytoplasmic 

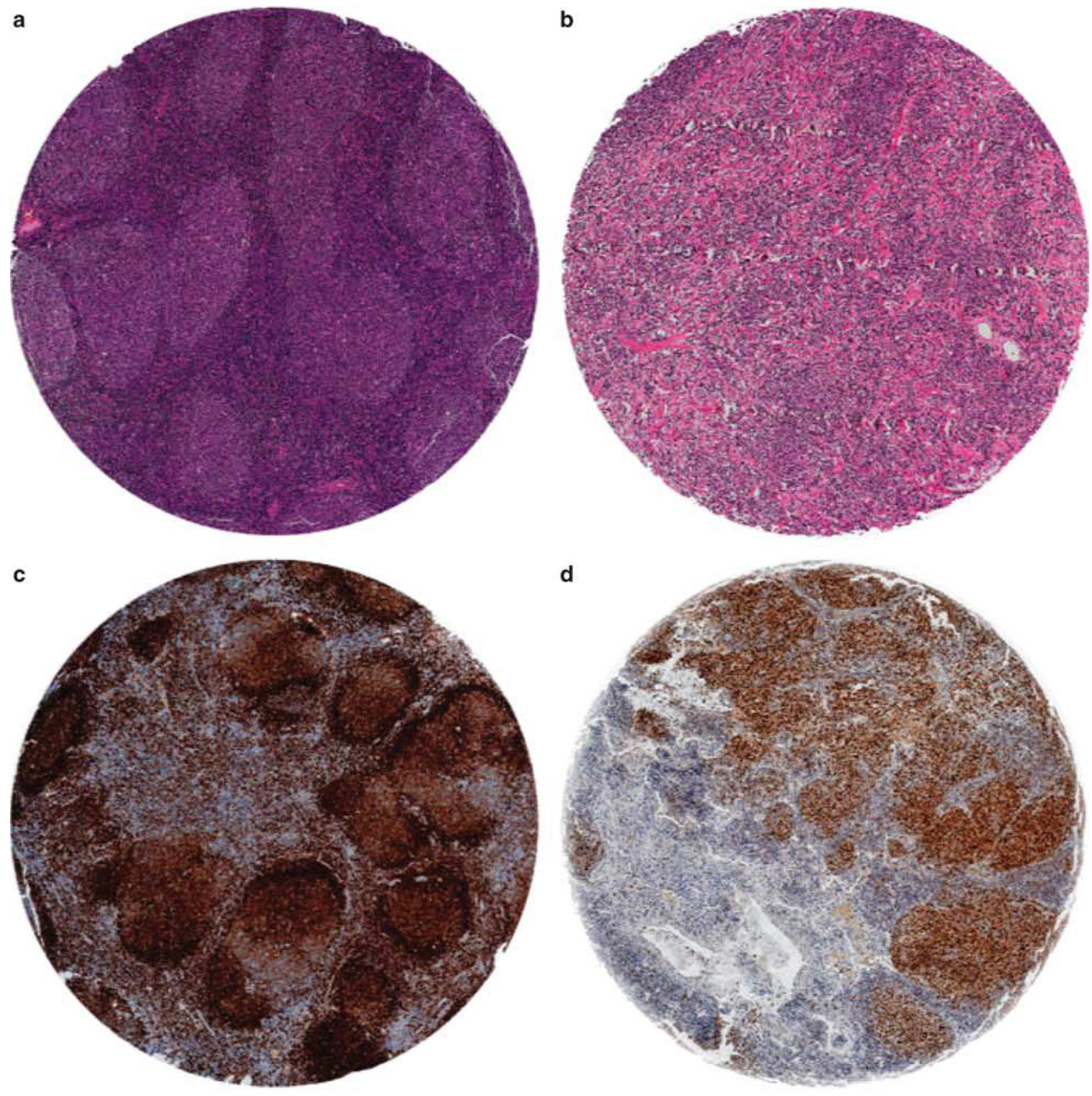

e

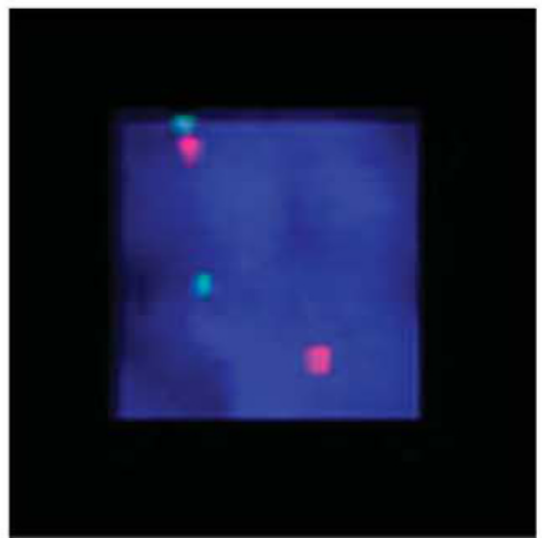

f

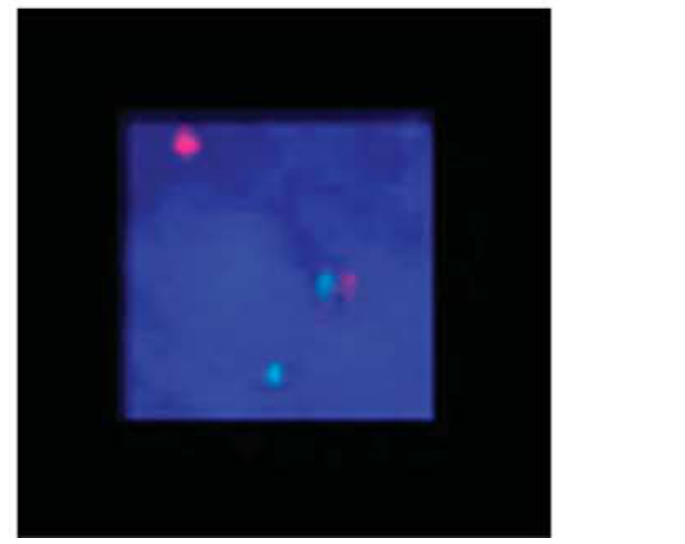

Figure 2 (a) Follicular lymphoma (Hematoxylin and Eosin). (b) follicular lymphoma with score $3+$ fibrosis (Hematoxylin and Eosin). (c) CD23 expression in neoplastic cells. (d) MUM1/IRF4-positive case. (e) and (f) FISH for BCL2 and BCL6 rearrangements, respectively. 
inclusions resulting from abnormal intracellular accumulation of immunoglobulin that were PAS-positive: two of these cases displayed monotypic expression for immunoglobulin light chain kappa or lambda by immunohistochemistry. In one case, these inclusions were so prominent that the lymphoma cells revealed 'signet ring' appearence.

A subset of the follicular lymphoma cases revealed admixed tingible-body macrophages, imparting a 'starry-sky' appearance to the neoplasm. These tumor-associated macrophages were found in 23 cases. In $10(5 \%)$ cases, there were more than five
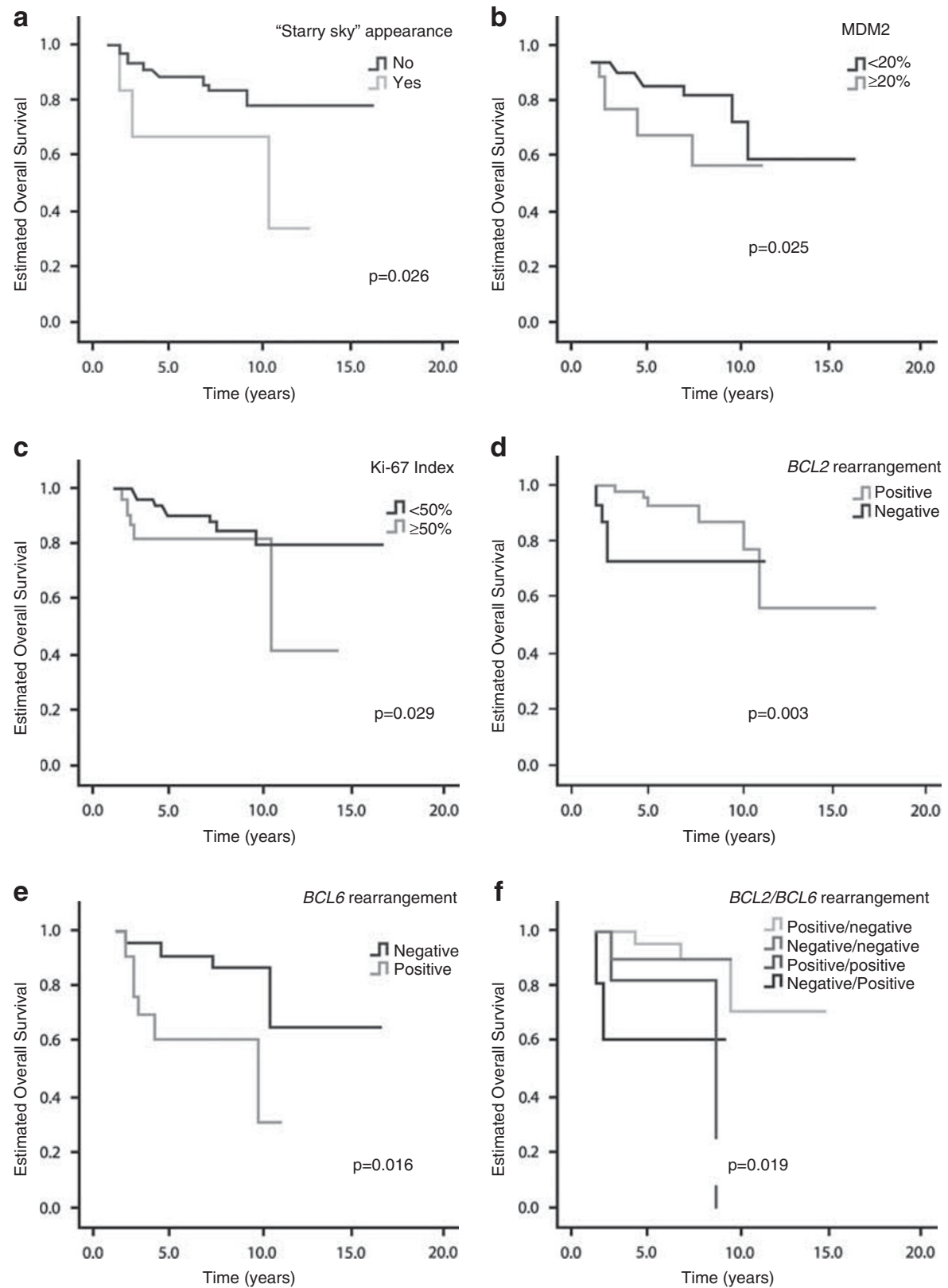

Figure 3 (a) Kaplan-Meier overall survival curve in the set of 121 patients selected according to starry-sky appearance. (b) Kaplan-Meier overall survival curve in the set of 102 patients selected according to MDM2. (c) Kaplan-Meier overall survival curve in the set of 119 patients selected according to Ki-67 index. (d) Kaplan-Meier overall survival curve in the set of 68 patients selected according to BCL2 rearrangement. (e) Kaplan-Meier overall survival curve in the set of 64 patients selected according to BCL6 rearrangement. (f) Kaplan-Meier overall survival curve in the set of 56 patients selected according to BCL2/BCL6 rearrangement. 
Table 3 Pathologic information on 200 cases of follicular lymphoma in young patients according to anatomic locations and age subgroups

\begin{tabular}{|c|c|c|c|c|c|c|c|c|}
\hline & \multirow[b]{2}{*}{$\begin{array}{l}\text { Extranodal } \\
\text { FL }\end{array}$} & \multicolumn{5}{|c|}{ Nodal FL (age groups) } & \multirow[b]{2}{*}{$\begin{array}{c}\text { Nodal } \\
F L+D L B C L\end{array}$} & \multirow[b]{2}{*}{ Total } \\
\hline & & $\leq 25$ & $26-30$ & $31-35$ & $36-40$ & Total & & \\
\hline Total & 20 & 11 & 18 & 59 & 85 & 173 & 7 & 200 \\
\hline \multicolumn{9}{|l|}{ Grade $(\%(+))$} \\
\hline 1 & $55(11)$ & $55(6)$ & $39(7)$ & $46(27)$ & 46 (39) & $46(79)$ & 0 & $45(90)$ \\
\hline 2 & $25(5)$ & $18(2)$ & $44(8)$ & $37(22)$ & $29(25)$ & $33(57)$ & $14(1)$ & $32(63)$ \\
\hline За & $10(2)$ & $9(1)$ & $11(2)$ & $15(9)$ & $20(17)$ & $17(29)$ & $29(2)$ & $16(33)$ \\
\hline $3 \mathrm{~b}$ & $10(2)$ & $18(2)$ & $6(1)$ & $2(1)$ & $5(4)$ & $4(8)$ & $57(4)$ & $7(14)$ \\
\hline \multirow{2}{*}{\multicolumn{9}{|c|}{$\begin{array}{l}\text { Histological findings }(\%(+)) \\
\quad \text { Fibrosis }\end{array}$}} \\
\hline & & & & & & & & \\
\hline $1+$ & 0 & 0 & $17(3)$ & $7(4)$ & $11(9)$ & $9(16)$ & 0 & $8(16)$ \\
\hline $2+$ & $5(1)$ & 0 & $11(2)$ & $7(4)$ & $6(5)$ & $6(11)$ & $29(2)$ & $7(14)$ \\
\hline $3+$ & $5(1)$ & 0 & $6(1)$ & $3(2)$ & 0 & $2(3)$ & $14(1)$ & $2(5)$ \\
\hline Mantle zone & $15(3)$ & 0 & $22((4)$ & $20(12)$ & $14(12)$ & $16(28)$ & $14(1)$ & $16(32)$ \\
\hline Diffuse areas & $10(2)$ & $18(2)$ & $11(2)$ & $8(5)$ & $8(7)$ & $9(16)$ & $100(7)$ & $12(25)$ \\
\hline \multicolumn{9}{|l|}{ TAM } \\
\hline $1+$ & 0 & 0 & $17(3)$ & $7(4)$ & $7(6)$ & 7 (13) & 0 & $6(13)$ \\
\hline $2+$ & $5(1)$ & $9(1)$ & 0 & $2(1)$ & $8(7)$ & $5(8)$ & 0 & $4(9)$ \\
\hline $3+$ & 0 & $9(1)$ & 0 & 0 & $1(1)$ & $1(2)$ & 0 & $1(2)$ \\
\hline \multicolumn{9}{|c|}{ FDC meshwork (\%(+/tested)) } \\
\hline Preserved & $14(2 / 14)$ & $20(2 / 10)$ & $43(6 / 14)$ & $44(24 / 54)$ & $53(34 / 64)$ & $41(66 / 162)$ & $33(2 / 6)$ & $43(70 / 162)$ \\
\hline Disrupted & $21(3 / 14)$ & $40(4 / 10)$ & $29(4 / 14)$ & $33(18 / 54)$ & $30(19 / 64)$ & $29(45 / 162)$ & $17(1 / 6)$ & $30(49 / 162)$ \\
\hline Absent & $64(9 / 14)$ & $40(4 / 10)$ & $29(4 / 14)$ & $22(12 / 54)$ & $17(11 / 64)$ & $19(31 / 162)$ & $50(3 / 6)$ & $27(43 / 162)$ \\
\hline \multicolumn{9}{|c|}{ Immunophenotype $(\%(+/$ tested $))$} \\
\hline CD10 & $89(16 / 18)$ & $91(10 / 11)$ & $86(12 / 14)$ & $95(54 / 57)$ & $89(70 / 79)$ & $91(146 / 161)$ & $71(5 / 7)$ & $91(167 / 184)$ \\
\hline MUM1 & $7(1 / 15)$ & $40(4 / 10)$ & $15(2 / 13)$ & $2(1 / 50)$ & $11(7 / 62)$ & $10(14 / 135)$ & $50(3 / 6)$ & $12(18 / 156)$ \\
\hline BCL6 & $100(17 / 17)$ & $100(11 / 11)$ & $100(16 / 16)$ & $100(55 / 55)$ & $92(69 / 75)$ & $96(151 / 157)$ & $100(7 / 7)$ & $97(175 / 181)$ \\
\hline BCL2 & $94(17 / 18)$ & $73(8 / 11)$ & $94(17 / 18)$ & $98(58 / 59)$ & $96(82 / 85)$ & $95(165 / 173)$ & $100(7 / 7)$ & $95(189 / 198)$ \\
\hline $\mathrm{CD} 23$ & $36(5 / 14)$ & $20(2 / 10)$ & $21(3 / 14)$ & $28(15 / 54)$ & $20(13 / 64)$ & $28(33 / 142)$ & $33(2 / 6)$ & $25(40 / 162)$ \\
\hline MDM2 ( $\geq 20 \%)$ & $13(2 / 15)$ & $30(3 / 10)$ & $23(3 / 13)$ & $10(5 / 50)$ & $10(6 / 62)$ & $15(20 / 135)$ & $67(4 / 6)$ & $17(26 / 156)$ \\
\hline Ki-67 ( $\geq 50 \%)$ & $15(3 / 20)$ & $40(4 / 10)$ & $11(2 / 18)$ & $24(14 / 59)$ & $26(21 / 82)$ & $24(41 / 169)$ & $100(7 / 7)$ & $26(51 / 196)$ \\
\hline \multicolumn{9}{|c|}{ FISH rearrangement (\%(+ /conclusive)) } \\
\hline BCL2 & $82(9 / 11)$ & $50(4 / 8)$ & $82(9 / 11)$ & $87(28 / 32)$ & $70(33 / 47)$ & $75(74 / 98)$ & $0(0 / 3)$ & $74(83 / 112)$ \\
\hline BCL6 & $0(0 / 10)$ & $33(2 / 6)$ & $12(1 / 8)$ & $16(5 / 31)$ & $24(11 / 46)$ & $21(19 / 91)$ & $50(2 / 4)$ & $20(21 / 105)$ \\
\hline
\end{tabular}

Abbreviations: DLBCL: diffuse large B-cell lymphoma; FDC: follicular dendritic cells; FISH: fluorescence in situ hybridization; FL: follicular lymphoma; TAM: tumor-associated macrophages.

and eighty-nine cases were positive for BCL2 $(n=198 ; 95 \%) ; 167$ expressed CD10 $(n=184$; 91\%); and 175 cases were positive for BCL6 $(n=181 ; 97 \%)$. Eighteen cases were positive for MUM1/IRF4 $(n=156 ; 12 \%)$. CD23 was positive in tumor cells in 40 cases ( $n=162 ; 25 \%$; Figure 2 c). In 35 cases, it was possible to demonstrate monoclonal imuglobulin kappa or lambda light chain expression.

Overall survival was worse in the 26 cases of follicular lymphoma $(n=156 ; 17 \%)$, where $>20 \%$ of cells were positive for MDM2 (13.1 $\pm 1.2-7.7 \pm 1.1$ years; $P<0.05$; Figure3b). MUM1/IRF4-positive cases (Figure 2d) also showed a trend towards decreased overall survival, but the small number of cases did not permit statistical confirmation of this association. No difference in outcome was noted with different levels of expression of BCL2, BCL6, and CD10, expression of CD23, or the amount of follicular dendritic cells present in the neoplastic nodules as assessed by CD23 immunostains. A Ki-67 index $\geq 50 \%$ had a negative impact on survival when compared with Ki-67 index $<50 \%$ (14.1 $\pm 0.7-9.9 \pm 1.4$ years; $P<0.05$; Figure 3c).

Fluorescence in situ hibridization. Interphase FISH for BCL2 and BCL6 was performed in 158 cases. BCL2 was conclusive in 112 cases for $B C L 2$ rearrangement with positive results in 83 cases (74\%; Figure 2e). BCL6 rearrangement was observed in 21 cases ( $n=105 ; 20 \%$; Figure $2 f)$. In 31 patients, it was not possible to determine either BCL2 or BCL6 translocations. Overall survival was worse in cases of follicular lymphoma with an absence of BCL2 rearrangement $(12.9 \pm 1.4-7.9 \pm 1.0$ years; $P<0.05$; Figure $3 \mathrm{~d})$ and the presence of $B C L 6$ rearrangement $(13.4 \pm 1.4-6.4 \pm 1.1$ years; $P<0.05$; Figure 3 e). In 97 cases, FISH analysis was evaluated for both BCL2 
Table 4 FISH results for BCL2 and BCL6 in 94 cases of follicular lymphoma in younger adults; correlation with clinical and pathological features

\begin{tabular}{|c|c|c|c|c|}
\hline FISH rearrangement: & BCL2-/BCL6- & $B C L 2-/ B C L 6+$ & $B C L 2+/ B C L 6-$ & $B C L 2+/ B C L 6+$ \\
\hline \multicolumn{5}{|l|}{ Clinical features $(\%(+/$ tested $))$} \\
\hline Gender: male & $50(9 / 18)$ & $27(3 / 11)$ & $41(24 / 59)$ & $22(2 / 9)$ \\
\hline Age $\leq 30$ & $22(4 / 18)$ & $18(2 / 11)$ & $17(10 / 59)$ & $22(2 / 9)$ \\
\hline FLIPI $\geq 3$ & $33(1 / 3)$ & $50(3 / 6)$ & $35(8 / 23)$ & $50(2 / 4)$ \\
\hline B symptoms & $50(2 / 4)$ & $57(4 / 7)$ & $26(6 / 23)$ & $50(2 / 4)$ \\
\hline Ann Arbor stage III-IV & $50(2 / 4)$ & $43(3 / 7)$ & $52(13 / 25)$ & $100(4 / 4)$ \\
\hline Bone marrow involvement & $0 / 3$ & $20(1 / 5)$ & $22(5 / 23)$ & $75(3 / 4)$ \\
\hline Elevated LDH level & $0 / 3$ & $20(1 / 5)$ & $10(2 / 20)$ & $50(1 / 2)$ \\
\hline Anemia & $25(1 / 4)$ & $60(3 / 5)$ & $19(4 / 21)$ & $0 / 2$ \\
\hline Histological and immunohistochemical features $(\%(+))$ & $\mathbf{n}=\mathbf{1 8}$ & $\mathbf{n}=\mathbf{1 1}$ & $\mathbf{n}=\mathbf{5 9}$ & $\mathbf{n}=\mathbf{9}$ \\
\hline Fibrosis & $6(1)$ & $9(1)$ & $8(5)$ & 0 \\
\hline Persistence of mantle zone & 0 & $9(1)$ & $19(11)$ & $22(2)$ \\
\hline Starry-sky appearance & $17(3)$ & 0 & $2(1)$ & $11(1)$ \\
\hline Presence of diffuse area & $50(9)$ & $27(3)$ & $3(2)$ & 0 \\
\hline Grade 3 staging & $67(12)$ & $45(5)$ & $17(10)$ & $11(1)$ \\
\hline BCL2 staining-positive cases & 94 (17) & $91(10)$ & $97(57)$ & $100(9)$ \\
\hline BCL6 staining-positive cases & $100(18)$ & $91(10)$ & $100(59)$ & $100(9)$ \\
\hline CD10-positive cases & $61(11)$ & $36(4)$ & $93(55)$ & $100(9)$ \\
\hline MUM1/IRF4-positive cases & $56(10)$ & $55(6)$ & $2(1)$ & 0 \\
\hline CD23-positive cases & $17(3)$ & $9(1)$ & $36(21)$ & $33(3)$ \\
\hline MDM2 $\geq 20 \%$ & $39(7)$ & $45(5)$ & $10(6)$ & 0 \\
\hline Ki-67 index $\geq 50 \%$ & $61(11)$ & $45(5)$ & $25(15)$ & $11(1)$ \\
\hline
\end{tabular}

Abbreviations: FISH: fluorescence in situ hybridization; FLIPI: follicular lymphoma international prognostic index; LDH: lactate dehydrogenase.

and $B C L 6$, and four groups were created according to the status of these translocations: BCL2 - /BCL6 $(n=18 ; 19 \%), \quad B C L 2+/ B C L 6-\quad(n=59 ; \quad 61 \%)$, $B C L 2-/ B C L 6+\quad(n=11 ; \quad 11 \%), \quad B C L 2+/ B C L 6+$ $(n=9 ; 9 \%)$. Associations of these groups with clinical and histological features at diagnosis are summarized in Table 4. Figure $3 f$ summarizes the survival among different groups according to $B C L 2$ and BCL6 translocations. Subgroup BCL2+/BCL6 demonstrated the highest mean survival (13.7 \pm 1.5 ), and the group $B C L 2-/ B C L 6+$ demonstrated the lowest mean survival $(6.5 \pm 2.0 ; P<0.05)$.

Hierarchical clustering. Applying unsupervised hierarchical clustering using pathological and molecular variables, our cases of follicular lymphoma in young adults could be categorized into two groups with different characteristics (Figure 4). Group A represented mainly follicular lymphoma cases with positivity for CD10, BCL6, BCL2, and $B C L 2$ rearrangement, and absence of BCL6 rearrangement. Group B was composed mostly of follicular lymphoma cases with higher grades, higher Ki-67 index, and expression of MDM2. Cases of group B also had a higher frequency of diffuse areas, presence of BCL6 rearrangement, and absence of $B C L 2$ rearrangement. No difference in overall survival was observed between these two groups, although the $P$-value supports a trend towards worse survival in group B. Association of life expectancy with potential prognostic markers are showed in Table 5.

\section{Discussion}

Non-Hodgkin lymphomas in adolescents and young adults present biological and epidemiological peculiarities that if better understood could help optimize their outcome. Follicular lymphoma is exceedingly rare in those $<15$ years $(1.5 \%$ of all non-Hodgkin lymphomas); its incidence increases with age and peaks between 55 and 59 years $(25 \%$ of all non-Hodgkin lymphomas). Recently, follicular lymphoma occurring in children was characterized in detail. ${ }^{8,9}$ We undertook the current study on an extensive cohort of young adults between the ages of 19 and 40 years, because of the dearth of knowledge regarding the clinicopathologic features and the outcome in patients diagnosed with follicular lymphoma in that age group.

Most follicular lymphoma cases in patients $<40$ years are manifested in the older age subgroups within this population (35-39 years) and are more common in female population. Interestingly, follicular lymphoma is more common in male individual during childhood, and with increasing age, there is a gender shift to female predominance. ${ }^{10}$ Forty-nine percent of our cases were between 36 and 40 years of age, and $56 \%$ were female subjects.

Follicular lyphoma generally involves not only the lymph nodes, but also the spleen, peripheral blood, and Waldeyer's ring. ${ }^{1}$ Bone marrow involvement is reported from 15 to almost $70 \%$, depending on histologic grade. In our series, bone marrow was infiltrated in $33 \%$ of the cases, with higher frequency at grade $2(44 \%)$. Follicular lymphoma 


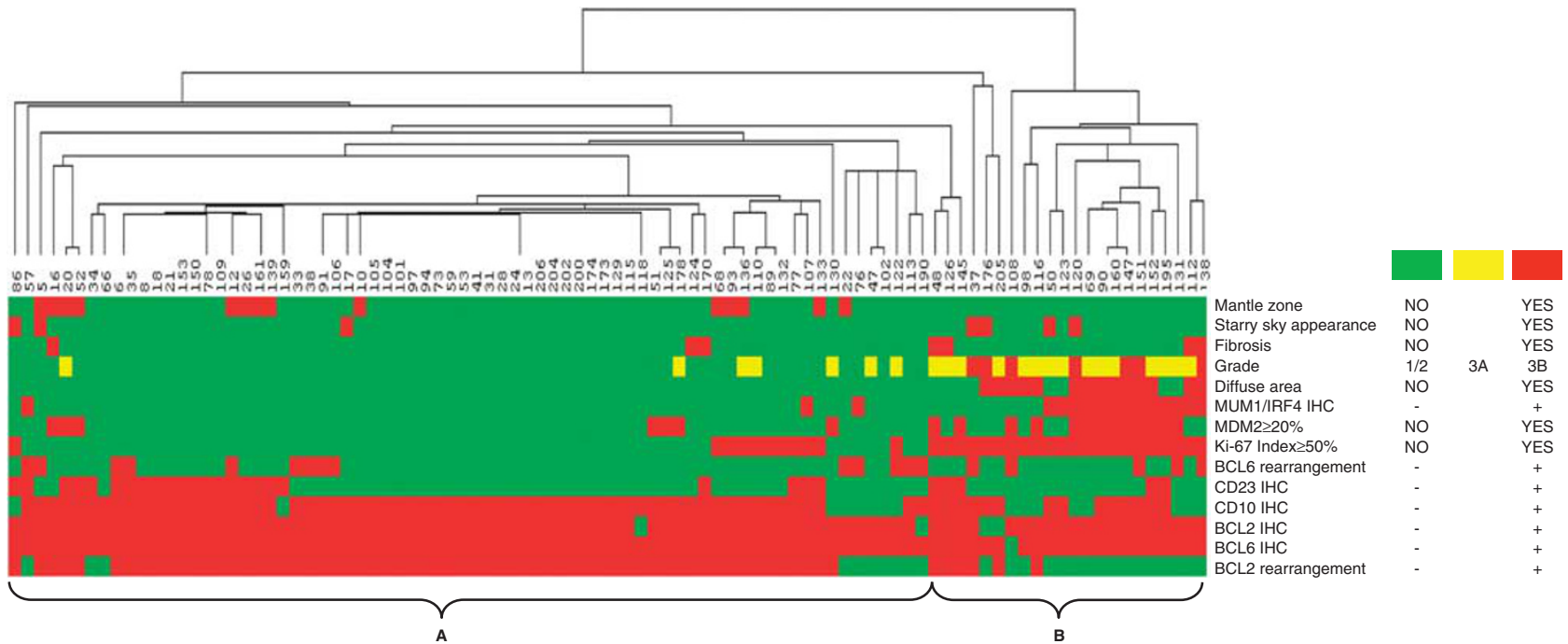

Figure 4 Unsupervised hierarchical clustering based on clinicopathologic variables of 94 cases of follicular lymphoma in young adults The cases can be divided into groups $\mathrm{A}$ and $\mathrm{B}$.

can also arise at other extranodal sites, that is, in the small intestine; some of these lymphomas may differ in their molecular properties and also in their clinical behavior from nodal and systemic conterparts. ${ }^{17}$ Three of our cases were intestinal follicular lymphoma-two in the duodenum and one in the stomach-all three achieved complete remission after treatment with no documented spread to other sites.

Lobetti-Bodoni et $a 1^{18}$ studied 153 follicular lymphoma patients $<40$ years in comparison with 850 patients $>40$ years, and found that younger patients had longer overall survival and longer cause-specific survival. They also showed that younger subjects had lower elevation of lactate dehydrogenase and less frequent primary extranodal localization, but more frequent bone marrow involvement. In their series, bone marrow involvement was $57 \%$ in young adults, which was very different from the $33 \%$ found in our series. We could speculate that the low frequency of bone marrow involvement in our cases could be related to unilateral bone marrow biopsy performed in most of our patients. Elevated lactate dehydrogenase was observed in similar proportions in both series (14 vs 11\%).

Follicular lymphoma is typically diagnosed in advanced stages, with only $26-33 \%$ of patients presenting stage I or II disease. ${ }^{2}$ Summerfield et $a l,{ }^{11}$ studying 46 follicular lymphoma patients under 40 years of age, found that $74 \%$ were Ann Arbor stages III and IV. In our series, these stages corresponded to $66 \%$ (56 of the 85 ).

Several prognostic parameters have been identified in an effort to predict outcome in patients with follicular lymphoma, including FLIPI, which divides follicular lymphoma cases into three groups with distinct survival probabilities. ${ }^{19}$ In our series, we found significant differences between low/intermediate $(<3)$, and high-risk FLIPI groups $(\geq 3)$ in terms of overall survival. Although currently the FLIPI 2 score is used, ${ }^{20}$ we were unable to apply this type of score in our cases due to incomplete availability of some clinical and biological parameters, which were not routinely collected at the time of diagnosis. These included size of the largest tumor mass and serum $\beta 2$-microglobulin level.

The prognostic significance of the follicular lymphoma microenvironment has been previosly studied. $^{21}$ Farinha et $a l^{22}$ suggested that a high number of tumor-associated macrophages $(\geq 15$ CD68 + macrophages/HPF) were correlated with a poor prognosis (5.0 years) in 12 of the 99 follicular lymphoma cases as opposed to 87 cases with $<15$ CD68 + macrophages/HPF (16.3 years). In this respect, we found more than five macrophages/ $\mathrm{HPF}$ in $5 \%$ of our cases and this was also correlated with poorer overall survival compared with the group with $\leq 5$ macrophages/HPF (7.6 vs 14 years, respectively). Tumor-induced fibrosis occured in $10 \%$ of our cases; one-fourth of these presented in cervical lymph nodes. As other indolent lymphomas hardly ever show accompanying sclerosis, this feature is helpful for histopathologists in establishing the diagnosis. ${ }^{1}$ It had no impact on overall survival in our hands, although a correlation of fibrosis with poor overall survival has been reported and was found to be independent of the FLIPI in advanced-stage follicular lymphoma. ${ }^{23}$ Diffuse areas were found in $12 \%$ of our cases. In some of these cases, the use of CD23 was of help, confirming that the tumor cells were growing outside of the follicules. These areas were composed mainly of centrocytes with very few centroblasts, and lacked significant impact on overall survival. It is important to reinforce that diffuse areas formed predominantly by large 
Table 5 Association of life expectancy with potential prognostic markers in young patients with follicular lymphoma

\begin{tabular}{|c|c|c|c|c|c|}
\hline & \multicolumn{2}{|c|}{ Estimated life expectancy } & \multicolumn{2}{|c|}{$95 \%$ Confidence interval } & \multirow[b]{2}{*}{$\mathrm{P}$-valu } \\
\hline & (years) & Deviation & Lower bound & Upper bound & \\
\hline General & 13.4 & 0.8 & 11.8 & 14.9 & \\
\hline \multicolumn{6}{|l|}{ FLIPI } \\
\hline$<3$ & 12.2 & 0.7 & 10.8 & 13.6 & 0.001 \\
\hline$\geq 3$ & 6.3 & 1.8 & 2.7 & 10.0 & \\
\hline \multicolumn{6}{|l|}{$L D H$} \\
\hline Normal & 13.1 & 0.5 & 12.1 & 14.1 & 0.001 \\
\hline Elevated & 7.4 & 1.6 & 4.2 & 10.5 & \\
\hline \multicolumn{6}{|l|}{ Anemia } \\
\hline No & 13.5 & 0.3 & 12.8 & 14.1 & 0.001 \\
\hline Yes & 5.8 & 1.4 & 3.1 & 8.6 & \\
\hline \multicolumn{6}{|c|}{ BM involvement } \\
\hline No & 13.7 & 0.3 & 13.1 & 14.2 & 0.003 \\
\hline Yes & 8.3 & 1.1 & 6.2 & 10.4 & \\
\hline \multicolumn{6}{|l|}{ Mantle zone } \\
\hline No & 11.5 & 0.7 & 10.1 & 12.9 & 0.90 \\
\hline Yes & 13.8 & 1.4 & 11.0 & 16.5 & \\
\hline \multicolumn{6}{|l|}{ Diffuse areas } \\
\hline No & 13.5 & 0.8 & 11.9 & 15.1 & 0.83 \\
\hline Yes & 4.5 & 0.4 & 3.7 & 5.3 & \\
\hline \multicolumn{6}{|l|}{ TAM } \\
\hline No and $1+$ & 14.0 & 0.7 & 12.6 & 15.4 & 0.04 \\
\hline $2+$ and $3+$ & 7.6 & 2.0 & 3.6 & 11.6 & \\
\hline \multicolumn{6}{|l|}{ Fibrosis } \\
\hline No and $1+$ & 13.2 & 0.9 & 11.5 & 14.9 & 0.63 \\
\hline $2+$ and $3+$ & 9.7 & 0.9 & 7.8 & 11.5 & \\
\hline \multicolumn{6}{|l|}{$C D 10$} \\
\hline- & 9.1 & 0.9 & 7.4 & 10.8 & 0.43 \\
\hline+ & 13.7 & 0.8 & 12.1 & 15.3 & \\
\hline \multicolumn{6}{|l|}{$B C L 6$} \\
\hline- & 6.6 & 1.5 & 3.7 & 9.5 & 0.60 \\
\hline+ & 13.0 & 1.0 & 11.1 & 15.0 & \\
\hline \multicolumn{6}{|l|}{ MUM1/IRF4 } \\
\hline- & 12.9 & 1.1 & 10.8 & 15.0 & 0.09 \\
\hline+ & 8.0 & 1.4 & 5.2 & 10.8 & \\
\hline \multicolumn{6}{|l|}{$C D 23$} \\
\hline- & 13.7 & 0.8 & 12.1 & 15.4 & 1.00 \\
\hline+ & 9.9 & 0.8 & 8.4 & 11.4 & \\
\hline \multicolumn{6}{|l|}{$M D M 2(\geq 20 \%)$} \\
\hline No & 13.1 & 1.2 & 10.7 & 15.5 & 0.02 \\
\hline Yes & 7.7 & 1.1 & 5.6 & 9.8 & \\
\hline \multicolumn{6}{|l|}{$K i-67(\geq 50 \%)$} \\
\hline No & 14.1 & 0.7 & 12.7 & 15.6 & 0.03 \\
\hline Yes & 9.9 & 1.4 & 7.0 & 12.7 & \\
\hline \multicolumn{6}{|c|}{ BCL2 rearrangement } \\
\hline- & 7.9 & 1.0 & 5.9 & 9.9 & 0.02 \\
\hline+ & 12.9 & 1.4 & 10.2 & 15.7 & \\
\hline \multicolumn{6}{|c|}{ BCL6 rearrangement } \\
\hline- & 13.4 & 1.4 & 10.6 & 16.2 & 0.01 \\
\hline+ & 6.4 & 1.1 & 4.2 & 8.7 & \\
\hline
\end{tabular}


Table 5 (Continued)

\begin{tabular}{|c|c|c|c|c|c|}
\hline & \multicolumn{2}{|c|}{ Estimated life expectancy } & \multicolumn{2}{|c|}{$95 \%$ Confidence interval } & \multirow[b]{2}{*}{$\mathrm{P}$-value } \\
\hline & (years) & Deviation & Lower bound & Upper bound & \\
\hline \multicolumn{6}{|c|}{ Follicular dendritic cells meshwork } \\
\hline Absent & 9.6 & 0.5 & 8.7 & 10.5 & 0.99 \\
\hline Disrupted & 8.9 & 0.7 & 7.5 & 10.3 & \\
\hline Preserved & 12.8 & 1.3 & 10.2 & 15.3 & \\
\hline \multicolumn{6}{|c|}{ Kappa/lambda restriction } \\
\hline- & 12.9 & 1.1 & 10.8 & 15.0 & 0.82 \\
\hline+ & 8.0 & 1.5 & 5.0 & 11.0 & \\
\hline \multicolumn{6}{|c|}{ CD10 vs $M U M 1$} \\
\hline$+1+$ & 8.5 & 1.6 & 5.3 & 11.7 & 0.22 \\
\hline$+1-$ & 13.5 & 0.9 & 11.7 & 15.3 & \\
\hline$-1+$ & 2.6 & 0.7 & 1.2 & 4.1 & \\
\hline$-1-$ & 10.0 & 0.2 & 9.7 & 10.4 & \\
\hline \multicolumn{6}{|c|}{$B C L 2$ vs BCL 6 rearrangement } \\
\hline$+1+$ & 7.5 & 1.6 & 4.4 & 10.7 & 0.02 \\
\hline$+1-$ & 13.7 & 1.5 & 10.8 & 16.7 & \\
\hline$-1+$ & 6.6 & 2.0 & 2.6 & 10.5 & \\
\hline$-1-$ & 7.6 & 0.8 & 6.1 & 9.1 & \\
\hline
\end{tabular}

Abbreviations: BM: bone marrow; FLIPI: follicular lymphoma international prognostic index; LDH: lactate dehydrogenase; TAM: tumorassociated macrophages.

transformed cells would require a separate diagnosis of diffuse large B-cell lymphoma.

Transformation from follicular lymphoma into an aggressive lymphoma, usually diffuse large B-cell lymphoma, occurs at a rate of $3 \%$ per year. ${ }^{24}$ Conconi et $a l^{25}$ reported histologic transformation in $26 \%$ at 14 years in a series of 281 cases treated in Switzerland. In our series, we observed concomitance of diffuse large B-cell lymphoma with follicular lymphoma in $7(4 \%)$ patients at the time of diagnosis. Four of these cases were grade 3B, 2 were grade $3 \mathrm{~A}$, and one was grade 2 . Thus far, we have had no documented histologic transformation in the remaining cohort of cases.

With respect to grade, we found no significant difference between groups graded as 1,2 , and $3 \mathrm{~A}$ in terms of overall survival. Only grade 3B cases showed significant worsening of overall survival. This is in accordance with a recent study by Wahlin et $a{ }^{26}$ who evaluated a population-based cohort of 505 follicular lymphoma patients in a broad age range (25-89 years) and found that grade 3A follicular lymphoma behaved like an indolent lymphoma. Others have confirmed similar findings. ${ }^{27}$ Jaglowski et $a l,{ }^{10}$ in a SEER review of follicular lymphoma in adolescents and young adults, cite that the relative frequency of low-grade follicular lymphoma increases with age due to the general trend of more aggressive lymphomas in the young population. In patients aged 15-24 years, grades 1 through 3 occur with approximately equal frequencies, whereas in the 35-39 age group, grade 1 represents $\sim 55 \%$ of diagnoses, followed by grade 2 at $30 \%$ and grade 3 at $18 \%$. In our series, the proportion of grade 1 follicular lymphoma by age subgroups showed only a slight variation: it was higher $(54 \%)$ in the younger age subgroup $(\leq 25$ years), diminished $(41 \%)$ in the following age subgroup (26-30 years), and increased again in older age subgroups, $31-35(44 \%)$ and $36-40$ years $(46 \%)$. This difference from previously reported series probably indicates that our cases are not related to the pediatric type of follicular lymphoma.

Follicular lymphoma cells typically express B-cell markers together with germinal center (GC) markers (CD10, BCL6, and HGAL). MUM1/IRF4, a post-GC $\mathrm{B}$-cells marker, usually is not present in neoplastic cells of follicular lymphoma. ${ }^{7,28-31}$ BCL2 protein is expressed in most follicular lymphoma, including cases lacking the $t(14,18)$ translocation. Variations in this immunoprofile have been reported and some of them are associated with prognostic value. High-grade follicular lymphoma that lack $t(14,18)$ were found to be frequently associated with a 3q27/ BCL6 rearrangement, and a CD10-negative and MUM1/IRF4-positive immunophenotype. ${ }^{32-34}$ In our cases, the expression of MUM1/IRF4 was seen in a minority of the cases $(12 \% ; 18+/ 156)$. In these cases, CD10 was negative in $37 \%$; there was lack of $B C L 2$ rearrangement in $89 \%$ and presence of BCL6 rearrangement in $35 \%$. Unlike Louissaint et al, ${ }^{9}$ who found all BCL2 rearrangement-negative/highprofoliferative index (BCL2-N/HPI) cases to be stage I among 58 adult follicular lymphoma studied ( $\geq 18$ years of age), in our series, just onethird were stage I follicular lymphoma. Liu et $a l^{8}$ found expression of MUM1/IRF4 in all pediatric follicular lymphoma cases involving the Waldeyer ring. We had five cases involving the tonsil, with no expression of MUM1/IRF4. Only one extranodal 
case occuring in the thyroid was positive for MUM1/ IRF4. CD23 expression in neoplastic cells can be observed in follicular lymphoma. ${ }^{35,36}$ In this series, CD23 was positive in $24 \%$ of the cases $(39+/ 163)$. No difference in outcome was noted with different levels of expression of CD23 in follicular lymphoma cells.

At the molecular level, 70-95\% of follicular lymphoma are reported to contain a translocation between chromosomes 14 (IGH region) and 18 (BCL2 region). ${ }^{37,38}$ In the present study, BCL2 rearrangement was present in 84 cases $(74 \%$; $n=112)$. Rearrangement of the BCL6 gene, initially thought to be specifically associated with diffuse large B-cell lymphoma, is observed in 6.4\% up to $14.3 \%$ of follicular lymphoma at the time of diagnosis, and may be prone to subsequent highergrade transformation. ${ }^{39}$ It is also suggested that BCL6 rearrangements could be related to adverse clinical outcomes. ${ }^{33,40}$ In our series, we observed that rearrangement in 21 cases $(20 \%$; $n=105)$. DiazAlderete et al, ${ }^{40}$ studying follicular lymphoma cases for BCL2 and BCL6 rearrangements by FISH on paraffin-embedded tissue sections, found positivity in $64(101+/ 158)$ and $14 \%(22+/ 156)$ of the cases, respectively. They also distributed their cases into four groups: BCL2 - /BCL $6-(32 \%), B C L 2+/$ BCL6 - (56\%), BCL2 - /BCL6 + (5\%), and BCL2+ / $B C L 6+(9 \%)$. In our series, these frequencies were $19,61,11$, and $9 \%$, respectively. In terms of histologic grades, the frequency of BCL2 rearrangement in our cases was higher in grade 1 follicular lymphoma (93\%), followed by grade 2 $(75 \%)$, grade $3 \mathrm{~A}(50 \%)$, and grade $3 \mathrm{~B}(11 \%)$. An opposite trend was detected in the frequency of BCL 6 rearrangment: $21,20,9$, and $50 \%$, respectively. We found five cases of high-grade lymphoma with features of follicular lymphoma presenting with BCL6, but not BCL2 rearrangments. Jardin et $a l^{34}$ studied 15 cases with BCL6 (3q27) rearrangement and absence of $\mathrm{t}(14 ; 18)$, and found that these cases had distinct pathological features in comparison with classical follicular lymphoma, such as more prominent nodal architecture and larger follicles.

An interesting finding in the current series was worse survival in follicular lymphoma cases in patients where MDM2 was expressed in $>20 \%$ of the neoplastic cells. Camacho et $a l^{41}$ also found worse survival in follicular lymphoma cases with higher expression of MDM2. ${ }^{41}$

It is important to state that this study is not based on cases with uniform and standardized treatment, and includes patients treated with different protocols, reflecting the absence of any standard approach to the treatment of follicular lymphoma.

In summary, according to our findings, follicular lymphoma in this age group (19-40 years) shows many similarities with follicular lymphoma in adults of older age, including frequency in anatomic sites, grading distribution, and adverse prognostic parameters like lactate dehydrogenase, bone marrow involvement, anemia, poor risk FLIPI, higher number of tumor-associated macrophages, grade 3B follicular lymphoma, and presence of BCL6 rearrangement.

\section{Acknowledgements}

We thank the Medical Centers and colleagues who provided the clinical and follow-up information: Francine de Agostinho, MD; Ana Maria Rebêlo, MD; Suley Vancine, MD; Rodrigo Maganha, MD; Henrique Pereira, MD; Rafael Gaiolla, MD; Alexandre de O Sales, MD; Sônia Lima Marcena, MD; Thiago Lopes, MD; Fábio Negretti, MD; Armando Antico Filho, MD; João Henrique Amaral e Silva, MD; Paula C. Abreu e Lima, MD; Siderley S Carneiro, MD; Samia Demachki, MD. We also extend thanks to Gabriela Gualco, MD, for her insights, Eduardo Queiroga, MD, for his help with FISH studies, and to Antonio Bruni for the statistical analysis.

\section{Disclosure/conflict of interest}

The authors declare no conflict of interest.

\section{References}

1 Klapper W. Pathobiology and diagnosis of follicular lymphoma. Semin Diagn Pathol 2011;28:146-160.

2 Relander T, Johnson NA, Farinha P, et al. Prognostic factors in follicular lymphoma. J Clin Oncol 2010; 28:2902-2913.

3 Armitage JO, Weisenburger DD. New approach to classifying non-Hodgkin's lymphomas: clinical features of the major histologic subtypes. Non-Hodgkin's Lymphoma Classification Project. J Clin Oncol 1998;16:2780-2795.

4 Fisher RI, LeBlanc M, Press OW, et al. New treatment options have changed the survival of patients with follicular lymphoma. J Clin Oncol 2005;23: 8447-8452.

5 Peterson BA, Petroni GR, Frizzera G, et al. Prolonged single-agent versus combination chemotherapy in indolent follicular lymphomas: a study of the cancer and leukemia group B. J Clin Oncol 2003;21:5-15.

6 Glas AM, Kersten MJ, Delahaye LJ, et al. Gene expression profiling in follicular lymphoma to assess clinical aggressiveness and to guide the choice of treatment. Blood 2005;105:301-307.

7 Harris NL, Swerdlow SH, Jaffe ES, et al. Follicular Lymphoma, In: Swerdlow EH, Campo E, Harris NL, et al. (eds) WHO classification of tumours of haematopoietic and lymphoid tissues, 4th edn. IARC: Lyon; 2008, pp 220-226.

8 Liu Q, Salaverria I, Pittaluga S, et al. Follicular Lymphomas in Children and Young Adults: A Comparison of the Pediatric Variant With Usual Follicular Lymphoma. Am J Surg Pathol 2013;37:333-343.

9 Louissaint A Jr, Ackerman AM, Dias-Santagata D, et al. Pediatric-type nodal follicular lymphoma: an indolent clonal proliferation in children and adults with high 
proliferation index and no BCL2 rearrangement. Blood 2012;120:2395-2404.

10 Jaglowski SM, Linden E, Termuhlen AM, et al. Lymphoma in adolescents and young adults. Semin Oncol 2009;36:381-418.

11 Summerfield GP, Wood KM, Taylor PR, et al. Survival in young patients (less than 40 years) with follicular lymphoma: a population based study by the Scotland and Newcastle Lymphoma Group. Leuk Lymphoma 2004;45:1149-1157.

12 Rueda A, Casanova M, Redondo M, et al. Has the time to come leave the 'watch-and-wait' strategy in newly diagnosed asymptomatic follicular lymphoma patients? BMC Cancer 2012;12:210.

13 Cox DR. Regression models and life-tables. J R Stat Soc 1972;187-220.

14 Kaplan EL, Meier P. Nonparametric estimation from incomplete observations. J Am Stat Assoc 1958; $457-481$.

15 de Hoon MJ, Imoto S, Nolan J, et al. Open source clustering software. Bioinformatics 2004;20: 1453-1454.

16 Saldanha AJ. Java Treeview-extensible visualization of microarray data. Bioinformatics 2004;20:3246-3248.

17 Yamamoto $\mathrm{S}$, Nakase $\mathrm{H}$, Yamashita $\mathrm{K}$, et al. Gastrointestinal follicular lymphoma: review of the literature. J Gastroenterol 2010;45:370-388.

18 Lobetti-Bodoni C, Rancoita PM, Montoto S, et al. (eds). The importance of age in prognosis of follicular lymphoma: clinical features and life expectancy of patients younger than 40 years. Proceedings of the 53rd American Society of Hematology Annual Meeting San Diego, CA, USA. Blood 2011;118:1593.

19 Solal-Celigny P, Roy P, Colombat P, et al. Follicular lymphoma international prognostic index. Blood 2004;104:1258-1265.

20 Federico M, Bellei M, Marcheselli L, et al. Follicular lymphoma international prognostic index 2: a new prognostic index for follicular lymphoma developed by the international follicular lymphoma prognostic factor project. J Clin Oncol 2009;27:4555-4562.

21 Solal-Celigny P, Cahu X, Cartron G. Follicular lymphoma prognostic factors in the modern era: what is clinically meaningful? Int $\mathrm{J}$ Hematol 2010;92:246-254.

22 Farinha P, Masoudi H, Skinnider BF, et al. Analysis of multiple biomarkers shows that lymphoma-associated macrophage (LAM) content is an independent predictor of survival in follicular lymphoma (FL). Blood 2005;106:2169-2174.

23 Klapper W, Hoster E, Rolver L, et al. Tumor sclerosis but not cell proliferation or malignancy grade is a prognostic marker in advanced-stage follicular lymphoma: the German Low Grade Lymphoma Study Group. J Clin Oncol 2007;25:3330-3336.

24 Montoto S, Davies AJ, Matthews J, et al. Risk and clinical implications of transformation of follicular lymphoma to diffuse large B-cell lymphoma. J Clin Oncol 2007;25:2426-2433.

25 Conconi A, Ponzio C, Lobetti-Bodoni C, et al. Incidence, risk factors and outcome of histological transformation in follicular lymphoma. Br J Haematol 2012;157:188-196.
26 Wahlin BE, Yri OE, Kimby E, et al. Clinical significance of the WHO grades of follicular lymphoma in a population-based cohort of 505 patients with long follow-up times. Br J Haematol 2012;156:225-233.

27 Horn H, Schmelter C, Leich E, et al. Follicular lymphoma grade $3 \mathrm{~B}$ is a distinct neoplasm according to cytogenetic and immunohistochemical profiles. Haematologica 2011;96:1327-1334.

28 Karube K, Guo Y, Suzumiya J, et al. CD10-MUM1 + follicular lymphoma lacks BCL2 gene translocation and shows characteristic biologic and clinical features. Blood 2007;109:3076-3079.

29 Piccaluga PP, Sapienza MR, Agostinelli C, et al. Biology and treatment of follicular lymphoma. Expert Rev Hematol 2009;2:533-547.

30 Younes SF, Beck AH, Lossos IS, et al. Immunoarchitectural patterns in follicular lymphoma: efficacy of HGAL and LMO2 in the detection of the interfollicular and diffuse components. Am J Surg Pathol 2010;34:1266-1276

31 Dogan A, Bagdi E, Munson P, et al. CD10 and BCL-6 expression in paraffin sections of normal lymphoid tissue and B-cell lymphomas. Am J Surg Pathol 2000;24:846-852.

32 Horsman DE, Okamoto I, Ludkovski O, et al. Follicular lymphoma lacking the $\mathrm{t}(14 ; 18)(\mathrm{q} 32 ; \mathrm{q} 21)$ : identification of two disease subtypes. Br J Haematol 2003;120: 424-433.

33 Guo Y, Karube K, Kawano R, et al. Bcl2-negative follicular lymphomas frequently have Bcl6 translocation and/or Bcl6 or p53 expression. Pathol Int 2007;57:148-152.

34 Jardin F, Gaulard P, Buchonnet G, et al. Follicular lymphoma without $t(14 ; 18)$ and with BCL-6 rearrangement: a lymphoma subtype with distinct pathological, molecular and clinical characteristics. Leukemia 2002;16:2309-2317.

35 Olteanu H, Fenske TS, Harrington AM, et al. CD23 expression in follicular lymphoma: clinicopathologic correlations. Am J Clin Pathol 2011;135:46-53.

36 Thorns C, Kalies K, Fischer U, et al. Significant high expression of CD23 in follicular lymphoma of the inguinal region. Histopathology 2007;50:716-719.

37 Montoto S, Lopez-Guillermo A, Colomer D, et al. Incidence and clinical significance of bcl-2/IgH rearrangements in follicular lymphoma. Leuk Lymphoma 2003;44:71-76.

38 Vaandrager JW, Schuuring E, Raap T, et al. Interphase FISH detection of BCL2 rearrangement in follicular lymphoma using breakpoint-flanking probes. Genes Chromosomes Cancer 2000;27:85-94.

39 Akasaka T, Lossos IS, Levy R. BCL6 gene translocation in follicular lymphoma: a harbinger of eventual transformation to diffuse aggressive lymphoma. Blood 2003;102:1443-1448.

40 Diaz-Alderete A, Doval A, Camacho F, et al. Frequency of BCL2 and BCL6 translocations in follicular lymphoma: relation with histological and clinical features. Leuk Lymphoma 2008;49:95-101.

41 Camacho FI, Bellas C, Corbacho C, et al. Improved demonstration of immunohistochemical prognostic markers for survival in follicular lymphoma cells. Mod Pathol 2011;24:698-707. 